\title{
Airline Passenger Information Systems and Process Improvements
}

\author{
Dave Raymond \\ Continental Airlines, Inc. \\ 1600 Smith Street, Suite 4700 Houston, Texas, 77002 \\ 713-324-6950 \\ Dave.Raymond@coair.com \\ Peter DeVries \\ University of Houston-Downtown \\ Department of Finance, Accounting, and CIS; Houston, TX 77002 \\ 713-221-8238 \\ devriesp@uhd.edu \\ P. Pete Chong \\ Chang Gung University \\ Department of Information Management; Taoyuan, Taiwan \\ 206-973-3248 \\ p.pete.chong@gmail.com
}

\begin{abstract}
In the highly competitive airline industry, differentiation between service offerings plays a crucial role in maintaining the existing customer base as well as attracting new clientele. There are a myriad number of ways to approach this goal. Separating the significant few from the trivial many involves listening to market demands and responding with the appropriate investment in capital and or, process improvements that provides solutions. This paper reviews the existing boarding environment and processes in and around the gate hold room area and proposes improvements through a threefold approach. First, add dynamic informational displays that update information regarding the boarding status. Second, reengineer the boarding sequence to reduce the time it takes to board and third, reengineer the process of loading carry-on luggage.
\end{abstract}

\section{INTRODUCTION}

Facing the high fuel costs and fierce competition for passengers, all airlines must consider ways to improve their operational efficiency to gain a competitive edge. For lowering the costs, airlines have been negotiating with pilots, attendants, and mechanics to lower their wage, benefit, and retirement costs; and the fabled stories of airlines removing pillows or even the legendary peanuts for the flight have been well publicized. To gain a competitive edge is a bit thornier. Companies may improve their on-time record and customer relationship to better their images and reputation; however, customer satisfaction may come from either increased service level or reduced frustrations - and thus a much more elusive to measure.

One of these measures is the performance in passenger processing. Savings of a few seconds here or there during passenger boarding add up to be the difference in performance -- both financially and on-time record. While these performance records may improve the image of an airline, reduced 
loading time has other benefits. We know that passengers would become restless if the loading takes too long; they also become frustrated whenever the needed information is not available. By streamlining the boarding process and providing the necessary information at the crucial time would reduce passenger discontent as well. This paper presents three opportunities to increase passenger processing and enhance the customer relationship. First, we will review and present alternatives to gate information displays. Here, we will recommend a combination of graphic, textural, and push technologies to portable devices that alert the passenger of the boarding status, regardless of when the passenger arrives at the gate holdroom. Secondly, we will review and present a plan for reducing the passenger boarding time that also reduces space conflicts between passengers. Airlines could not only reduce time to board, but develop a better customer relationship by reducing the inevitable people and luggage conflicts that occurs today during adjacent row boarding. Lastly, we will present an option whereby flight attendants assist with the loading of carry-on luggage.

\section{EXISTING PASSENGER BOARDING ENVIRONMENT}

The typical airline boarding process begins with passengers arrive the gate departure lounge (called gate holdroom) and wait for boarding. Passengers would be allowed to board only after the row numbers of their seats are called out but then still have to get in line to board. For a passenger who arrives at the gate holdroom late, the most frequently asked question (i.e., requested information) is the row that are currently been boarded. Additionally, passengers typically want to know whether a flight will leave on time. Currently the information is given through gate agents or passed around by other passengers. If these data can be provided to passengers through other means, agents can be freed to take care of other urgent matters.

The main cabin boarding sequence involves the logical progression from the back of the airline to the front. Unfortunately, even logical as this sounds, and as most people can attest to, it still leads to space conflicts related to seating as well as placement of luggage in the overhead bins. For example, since the isle is so narrow, if a person on isle 10 is having trouble loading carry-on luggage or cannot find the right seat, then everyone who tries to go to isle 11 and higher would be held up. Suppose a person who sits at the isle seat arrives before the passenger who is assigned the window seat at the same row, the isle-seat passenger invariably would have to stand up, get out of the seat, let the window-seat passenger in, then reseat. This delay further adds frustration to those who have to move ahead.

Finally, passengers today have to carry, roll, and in some cases, drag luggage that is too heavy and too large to be placed in the overhead bins. Some airlines have responded to this problem by increasing the size of the overheads to allow for perpendicular placement - relative to the aircraft centerline - of luggage into the bins, thus increasing typical capacity by one piece of luggage. However, the narrow isle presents an obstacle to luggage and causes delay. The vertical lift is still difficult for some. It has been measured that while a normal luggage loading could be around 20 seconds, a problematic one could add another minute to the seating process.

\section{GATE HOLD ROOM INFORMATION SYSTEM DISPLAYS - CRM FOR A WAITING CROWD}

With respect to e-CRM, Jiang (2003) stated that "e-CRM involves far more than automating processes in sales, marketing, and service and then increasing the efficiency of these processes. It involves conducting interactions with customers on a more informed basis and individually tailoring 
them to customer's needs.” As the airlines leveraged the Internet as a means to reduce ticket fees, the airline industry has invested heavily in technologies related to self service check-in since 1995. Reducing costs was not the only motivation, however; customer service was enhanced through enabling customers to select seat and print boarding pass at home thus negating the need to stop at the ticket counter. Further, regulations require such investment to increase security level. For example, airlines are required to match stowed luggage with passengers who are physically on the flight (positive bag match). Here, a substantial investment in wireless technologies was introduced in order to facilitate communication between the boarding process and luggage loading.

Since a lot of customer frustrations are generated through waiting and lacking information, it would be logical to take advantage of this positive bag matching technology to the gate hold room to provide customers with "a good experience however and whenever they choose to contact you is a key part of managing relationships with them.” (Jiang 2003) Although most airlines do provide information in flight number and time, passengers want way more than that. According to surveys to attendants, the most frequently asked questions include whether they are at the right gate, whether the flights are on time, and the rows that are currently boarding. In a study of passenger flows through a terminal, Takakuwa and Oyama (2002) note that passengers spend $48 \%$ of time in terminal buildings traveling to gates while spend $25 \%$ of their time waiting. Some of the waiting time apparently is spent on waiting while others were boarding.

Obviously, once a passenger is seated, s/he can proceed to sleep or get into a different mood to enjoy the flight. Thus, reducing this potentially frustrating time would improve customer satisfaction. Airlines may use electronic flat panel monitors set at locations in and around the gate counter as well as near the doorway to the jet way to display real-time status of the boarding process as well as other up-to-the-minute loading information for customers. For example, graphical information - a seat map displaying a count down of passengers that have boarded - or textural, displaying the row number of the boarding process, or both. This information could be extended to portable devices as well, cueing a passenger that the boarding process has stared.

Automating the delivery of boarding information frees the customer service agent from the mundane task of answering the same question repeatedly. This allows for the agent to focus tasks centered around getting the flight out on time. It is anticipated that coding rework would need to occur to provide the 'count down' function involving the seat map, but the basic information is already available. Other anticipated work involves the purchase, mounting, electrical work related to installation of the flat panel displays. Some airlines have adopted 16 × 9 aspect ratio displays mounted with the long axis up as the most efficient way to display graphical and textural information.

\section{BOARDING PROCESS STUDIES}

Anyone that has flown recently knows that boarding 150 or more passengers into a metal tube designed to have the characteristics of a bullet seems more like strapping on a too tight bathing suit. Boarding an aircraft can be a very tight fit. Compromises were made between efficiency and space that has been worked out over the past 40 years that resulted in what we have today. Airline aisles and seating, for many Americans, is simply too small. Some carriers have responded by increasing the 'pitch' - the distance between rows from front to back - in order to provide a more comfortable

experience. However, this has consequences that reduce capacity, and therefore revenue. In fact, some carriers have reversed this and increased seat count in order to remain viable. 
Given this environment, any improvement in the boarding process can provide time efficiencies that will improve an airlines on-time performance. All the carriers understand that the most efficient use of their aircraft means developing strategies for higher aircraft utilization. One way to do this is to drive efficiencies into the aircraft boarding process.

Prior to 2000, there was a limited amount of material regarding passenger boarding. However, Landeghem and Beuselinck (2002) took a detailed look at the process. They focused on short haul flights with seating configurations of six across. Modeling the theoretical boarding time was developed as triangular distributions (Kelton et al. 1998). This assumes that passengers arrive at the aircraft door every six seconds; thus, seating 100 people could take as little as 10 minutes. Boarding time starts as soon as the first passenger enplanes, and is completed when the last passenger is seated. As the authors noted, however, the design of the typical short haul aircraft does not facilitate comfortable boarding because overhead bins that span seats require passengers to stand in the aisle while storing their luggage. Because of the narrow aisles, any disruption in seating causes passengers to queue. Realistically, then, the anticipated range of boarding times was established between ten and thirty minutes.

Forty seven separate boarding simulations were run and data was collected. Simulation results show that boarding by row and in descending order would produce the highest boarding time. On the other hand, boarding passengers individually by their row and seat number, from window to center aisle and in descending order would produce the lowest boarding time. Authors recognize that this would probably be impractical in the real world, since families and collogues who travel together would like to board together.

Airlines today typically group rows together and call out a row range - rows 23 to 18 for example. If the airline chooses to stick with the tried and true 'block' method - the study defined a block as being a group of full rows, authors recommend keeping the blocks in the two to six range. They also noted that "half blocks" -- or one side of the center aisle -- would be even better. Our proposals will take this idea one step further.

Leveraging the Van Landeghem and Beuselinck study, America West Airlines - now joined with UsAir to become USAirways - recently completed a study and implemented the result during 2003 (Menkes et al. 2005). This study focuses on the frequency of interference between passengers rather than time. It defines two types of interferences: seat and aisle. Seat interference occurs when a passenger seated close to the aisle block other passengers seated in the same row; aisle interference occur when passengers stowing luggage block access to other passengers seeking their seat.

Menkes et al. broke down the analysis into six phases: development of an integer-programming to understand the problem and to create general patterns; testing of the patterns using simulation models more details of the actual airplane boarding procedure; improvement and refinement of these models to accommodate practical factors and limits of implementation; analysis of the results to determine best boarding procedure; testing and fine tuning of the recommended procedures; and finally, implementation and validation of the proposed boarding procedures. The number of interferences was collected through direct observation and by recording a boarding sequence. This data was used as an input to a mathematical model. Once in the model, additional simulations and theories were tested.

The final outcome from the study results in a "reverse pyramid" strategy for boarding. By loading from window to aisle and breaking down the passenger load into six grouping segments, the average 
number of interferences went from 72.22 - back to front with six groups- to 2.94 with the outside-in scheme. This outside-in loading plan resulted in a 37\% reduction in boarding times with two gate agents and a $25 \%$ reduction using a single agent.

\section{REENGINEERING THE BOARDING PROCESS}

Although efficient, there is the real possibility that the reverse pyramid plan would meet resistance when families and colleagues traveling together are broken up during the boarding process. Therefore, although efficient, practical application in the real world would require exceptions that could diminish the reverse pyramid loading scheme’s effectiveness.

Reviewing the data from the Landeghem / Beuselinck study the 'by_halfrow_alt_2' loading scheme, loading by alternating half rows yields excellent boarding metrics. With a $100 \%$ load factor, loading can occur in as little as 15.79 minutes. At a 62\% load, passengers can be boarded in as little as 10.25 minutes. The Landeghem / Beuselinck study does not provide implementation details of such a loading scheme, but one can envision the passengers being equipped with a colored loading card, or a colored indicator on the boarding pass. Only two (2) colors would be required- for example: red and blue. During the boarding period, the customer service agent would call all passengers with the 'red' card, and then after these passengers are seated, then call all passengers with a 'blue' card. Tied to this would be a simple display with two (2) divisions. The first division would contain the number, and the second would contain the color of the group boarding. In order to sequence the passengers, and to encourage back to front boarding, the number display would count down starting from row 23 for example. Boarding would start with a color selection, followed by a row number. Remember the Landeghem / Beuselinck plan loads alternate half rows. Therefore, when the passengers in the 'red' group are called, we would be boarding row 7, seats ABC; row 5, seats DEF; row 3, seats $A B C$, etcetera. Then the same pattern for rows $6,4,2 \ldots$ and so on.

Although this loading plan does not completely eliminate breaking up families and business collogues traveling together, more folks are grouped together - specifically by boarding all within a half row. Recent data was collected in order to capture and understand boarding durations as they exist today. Table A represents the actual loading time for ten flights during September, 2005. Data shows that the current back to front by groups of rows is not terribly efficient. Average boarding time is calculated at 39 minutes and the average per passenger loading time is 3.4 passengers per minute. Certainly, taking into account the reduction in loading time described previously, there is room for improved boarding efficiency. 


\begin{tabular}{|c|c|c|c|c|c|c|c|c|c|}
\hline Date & $\begin{array}{c}\text { Flight } \\
\text { Numbe } \\
\mathbf{r}\end{array}$ & From & To & $\begin{array}{l}\text { Aircraft } \\
\text { Capacity }\end{array}$ & $\begin{array}{c}\text { Number of } \\
\text { Passenger } \\
\text { s }\end{array}$ & $\begin{array}{c}\text { Boardin } \\
\text { g Start }\end{array}$ & $\begin{array}{l}\text { Boardin } \\
\text { g Finish }\end{array}$ & $\begin{array}{c}\text { Total } \\
\text { Elapse } \\
\text { Time }\end{array}$ & $\begin{array}{c}\text { Passengers } \\
\text { Boarded I } \\
\text { Per Min }\end{array}$ \\
\hline $9 / 15 / 200$ & & Hom & & & & & & & \\
\hline $\begin{array}{c}5 \\
9 / 15 / 200\end{array}$ & 1 & $\begin{array}{c}\mathrm{e} \\
\mathrm{Hom}\end{array}$ & DEN & 124 & 112 & 5:04 & $5: 32$ & 0:28:00 & 4.0 \\
\hline $\begin{array}{c}5 \\
9 / 15 / 200\end{array}$ & 2 & $\begin{array}{c}\mathrm{e} \\
\mathrm{Hom}\end{array}$ & SEA & 154 & 136 & $5: 22$ & $6: 00$ & 0:38:00 & 3.6 \\
\hline $\begin{array}{c}5 \\
9 / 15 / 200\end{array}$ & 3 & $\begin{array}{c}\mathrm{e} \\
\mathrm{Hom}\end{array}$ & ORD & 155 & 121 & 5:01 & $5: 32$ & 0:31:00 & 3.9 \\
\hline $\begin{array}{c}5 \\
9 / 19 / 200\end{array}$ & 4 & $\begin{array}{c}\mathrm{e} \\
\mathrm{Hom}\end{array}$ & EWR & 150 & 146 & $4: 08$ & $4: 40$ & 0:32:00 & 4.6 \\
\hline $\begin{array}{c}5 \\
9 / 19 / 200\end{array}$ & 5 & $\begin{array}{c}\mathrm{e} \\
\mathrm{Hom}\end{array}$ & EWR & 150 & 120 & $3: 33$ & 4:07 & 0:34:00 & 3.5 \\
\hline $\begin{array}{c}5 \\
9 / 19 / 200\end{array}$ & 6 & $\begin{array}{c}\mathrm{e} \\
\mathrm{Hom}\end{array}$ & CLE & 112 & 112 & $4: 25$ & $5: 00$ & 0:35:00 & 3.2 \\
\hline $\begin{array}{c}5 \\
9 / 19 / 200\end{array}$ & 7 & $\begin{array}{c}\mathrm{e} \\
\mathrm{Hom}\end{array}$ & $\mathrm{IAH}$ & 112 & 112 & $5: 15$ & $6: 05$ & 0:50:00 & 2.2 \\
\hline $\begin{array}{c}5 \\
9 / 19 / 200\end{array}$ & 8 & $\begin{array}{c}\mathrm{e} \\
\mathrm{Hom}\end{array}$ & CLE & 175 & 175 & $5: 10$ & $5: 57$ & $0: 47: 00$ & 3.7 \\
\hline $\begin{array}{c}5 \\
9 / 19 / 200\end{array}$ & 9 & $\begin{array}{c}\mathrm{e} \\
\mathrm{Hom}\end{array}$ & $\mathrm{IAH}$ & 124 & 119 & $4: 57$ & $5: 36$ & 0:39:00 & 3.1 \\
\hline 5 & 10 & $\mathrm{e}$ & CLE & 155 & 139 & $4: 41$ & $5: 37$ & $0: 56: 00$ & 2.5 \\
\hline
\end{tabular}

Table 1: Actual loading times for ten flights during September, 2005

\section{LOADING CARRYON LUGGAGE}

Part and parcel of loading people onto aircraft, loading carry-on luggage leads to space conflicts albeit overhead bin space. Although most airlines have improved their luggage delivery performance, many passengers would rather have the luggage with them, particularly on short duration trips. This eliminates the stop at the luggage carousel and helps speed departure from the airport. Here our focus of improvement is the loading of carry-on luggage. The recommendation is to offer as part of standard service, the loading of carry on luggage for families with children, senior citizens, and finally, anyone needing help.

Who would load the luggage? The suggestion here would be the flight attendants. They typically assist with this process today. In the half row alternate loading plan, attendants would be positioned to offer help to passengers with luggage, whether the passenger asks for assistance or not. Of course, this idea of concierge is nothing new in the hotel industry so why not extend this to the boarding process. Passengers would see this service see a clear, straightforward benefit and an added service. Combine this with the Landeghem / Beuselinck alternating half row board plan, and the passenger experience becomes simplified and streamlined with an improved level of service. 


\section{CONCLUSIONS AND FUTURE RESEARCH}

Some of the proposals presented here need further study and refinement. The technical elements regarding the proposed gate information display will be further elaborated in a following paper. The Landeghem / Beuselinck passenger loading simulations are sound and detailed tests that this paper stands by and recommends. Specifically, the recommendation of this paper is to utilize the 'by half row, alternating' loading plan. Having the flight attendants assist with the loading of luggage arguably needs no test as this is a recommended 'best practice' when assisting passengers. Taken together, all of the concepts represented here are straightforward and logical with the intent on improving the passenger experience, and of course, the airlines bottom line.

\section{REFERENCES}

Jiang, H.W. (2003) “Application of e-CRM to the Airline Industry," Proceedings to the Ninth Australasian World Wide Web Conference

Kelton, W.D., R.P. Sadowski, and D.A. Sadowski (1998) Simulations with Arena, Boston, MA: WCB McGraw-Hill

Landeghem, H.V. and A. Beuselinkck (2002) Reducing passenger boarding time in airplanes: A simulation based approach. European Journal of Operational Research, Vol. 142, 2002, pp. 294-308.

Takakuwa, S. and T. Oyama (2003) Modeling people flow: simulation analysis of internationaldeparture passenger flows in an airport terminal. Proceedings to Winter Simulation Conference, pp. 1627-1634

Van den Briel, MHL, J.R. Villalobos, G.L. Hogg, T. Lindemann, and A.V. Mulé (2005) America West Airlines Develops Efficient Boarding Strategies. Interface, 35(3), pp. 191-201 